\title{
CROSS-OVERS, SPERM REDUNDANCY AND THEIR CLOSE ASSOCIATION
}

\author{
JACK COHEN \\ Department of Zoology and Comparative Physiology, The University, \\ Birminghom B15 2TT, England
}

Received 20.vii.73

\begin{abstract}
SUMMARY
Numbers of chiasmata in the production of each gamete are closely related to the proportion of gametes which fail to function ( $r=0.81$ for 24 species). Gamete redundancy and chiasma frequency fail to correlate with chromosome number, DNA weight/nucleus, or the weight or age of the animal at puberty, as closely as with each other. Implications and corollaries are considered, and it is concluded that most gametes are functionless by-products of a necessarily faulty production system.
\end{abstract}

IN 1967 I suggested that a faulty process associated with chiasmata (crossingovers) might account for the large excess of gametes, particularly sperms. This might have gone undetected by geneticists because all zygotes examined (usually as adults) would show no evidence of such faults, if gametes with these faults never fertilise. So production as well as utilisation errors might lead to wastage of the majority of gametes (Cohen, 1967).

Comparison of the logarithm of sperm " redundancy" with the number of chiasmata involved in the production of each sperm, for a variety of species, could test this idea. As chiasma number increases linearly, so the proportion of non-faulty sperms would fall exponentially, and so the total number required for each fertilisation would rise exponentially. In 1967 I had only located mean chiasma frequency $(\mathrm{C})$ and sperm redundancy $(\mathrm{R})$ for seven species. One unpublished chiasma frequency and a preliminary sperm number investigation gave nine points and a correlation coefficient $r=0.90$.

Since then I have found many more figures, and the picture they produce is a very significant one (fig. 1). There are 33 points for 24 animal species, and correlation coefficient $r=0.87$ (and Spearman rank correlation is 0.81 ) if different workers with the same species are considered separately, or 0.81 (and 0.77) if they are considered together as a mean for the species. For 28 degrees of freedom $\mathrm{P}<0.00001$ (some points are not independent) and for 22 degrees of freedom $P<0.0001$. There is therefore no question that mean chiasma frequency and sperm redundancy are very highly associated.

If this association does reflect causality, if a chiasma-associated phenomenon requires multiplicity of sperms because only a fraction " work", then the regression of $\log \mathrm{R}$ on $\mathrm{C}$ gives more information. The slope of the association is a measure of the increase of $\log R$ for one cross-over, and suggests that a third $(0 \cdot 29)$ of chiasmata give unacceptable products. The height of the line, as judged by the $\mathrm{Y}$ intercept, suggests that utilisation problems on average require about fifty "good" sperms to be offered for one to fertilise. So for organisms with high $\mathrm{C}$, like man, fig. 1 suggests that 


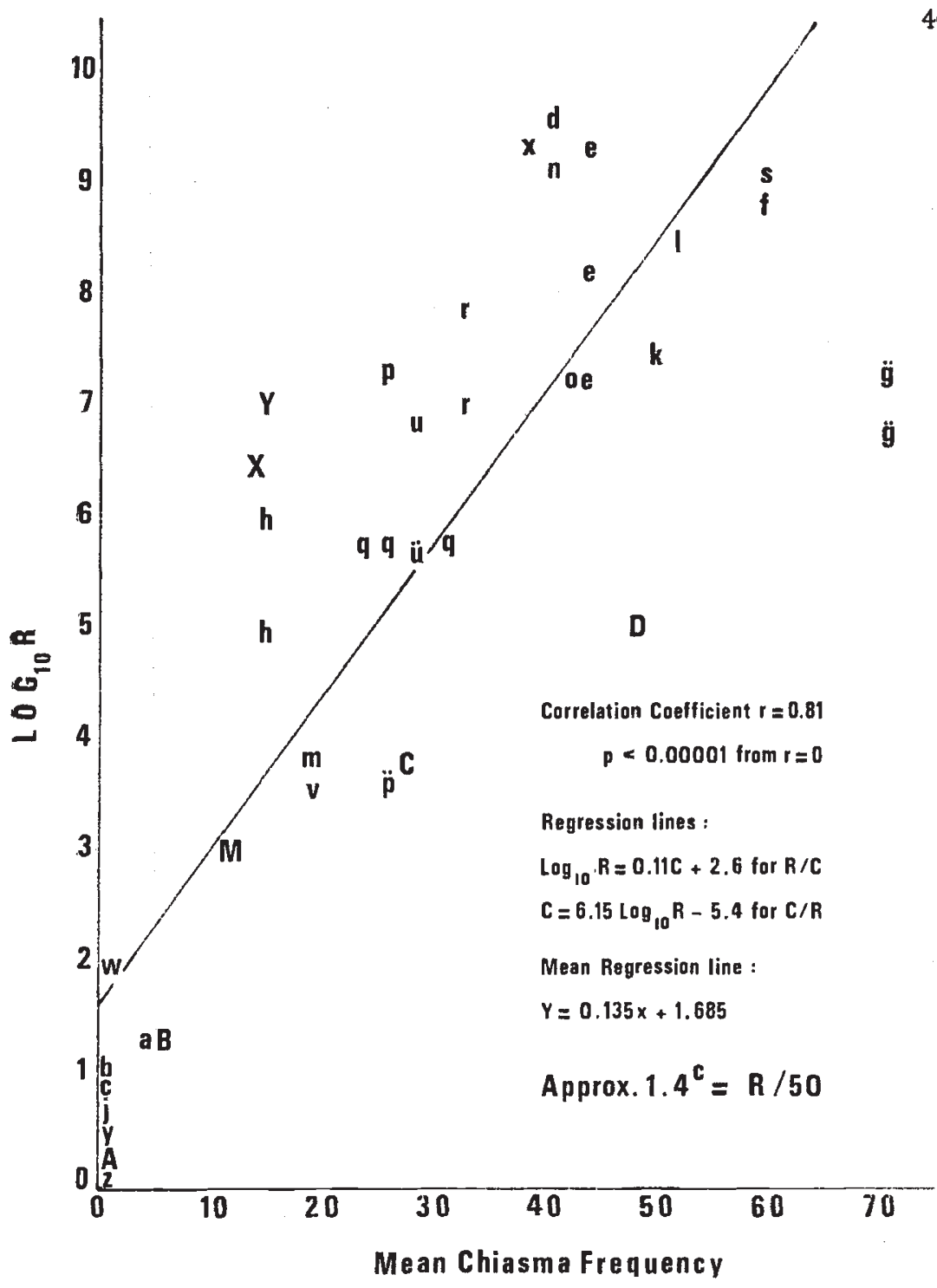

FiG. 1.-Gamete redundancy (R) and chiasma frequency/meiosis (C) in the production of each gamete, for a variety of species. The theory predicts $\log R \alpha C$. Sperm redundancy, or at least sperm excess $R$, is measured as $\frac{\text { no. of sperms }}{\text { no. of zygotes }}$ for one mating. All organisms for which $\mathbf{I}$ have sperm $\mathbf{C}$ and $\mathbf{R}$ appear in lower case (all appear in Cohen, 1971 unless noted) : a Aedes, b Apis, c Asplanchna, d Bos, e Canis (C, Eliasson et al., 1967), f Capra (C, Datta, 1970), g Cavia, h Cricetulus, j Drosophila, k Felis (C, Robinson, 1959), 1 Homo, $m$ Locusta, n Macaca mulatta, o Macaca nemestrina, p Mesocricetus, q Mus, r Oryctolagus, s Ovis, u Rattus (R, Adler and Zoloth, 1970), v Schistocerca, w Steatococcus, x Sus, y Dahlbomina ( $\mathrm{R}$ and C, Wilkes, 1965), z Aculus (R and C, Oldfield et al., 1972). ' refers to figures derived from animals electrically stimulated to ejaculate, and which on other grounds are considered low. Oocyte wastage is measured as $\frac{\text { oocytes entering meiosis }}{\text { zygotes }}$ or as " nurse cells" egg cells for insects: A Forficula, B Drosophila, C Mus, D Homo. M is pollen grains per seed/mean chiasma frequency for Prunus avium. $\mathrm{X}$ and $\mathrm{Y}$ are total egg production/mean chiasma frequency for Crassostrea (" $\mathrm{R}$ " and $\mathrm{C}$, Longwell and Stiles, 1968) and Mytilus ("R" and C, Ahmed and Sparks, 1970). 
only one of millions of sperms may be free from chiasma-associated problems; there would be about a hundred of these in a normal human ejaculate.

Correlations do not necessarily reflect direct causality; both $\mathbf{R}$ and $\mathbf{C}$ might be dependent upon a third variable. Four possibilities of such an indirect correlation have been considered: they are $(a)$ chromosome number, (b) whole animal size, (c) DNA weight/cell, and (d) time before maturation of the gonads. The correlations of $\mathbf{C}$ and $\mathbf{R}$ with these four variables are set out in table 1. Although this test is not critical for such a partial sampling (the data sets for each correlation are from differing species lists) nevertheless it is the best method for a first approximation to a multi-dimensional analysis. Certainly the method easily compares $\log _{10} R / C$ correlations with others.

TABLE 1

Table of correlations. Correlations include all the animal species for which $R$ or $C$ has been located in

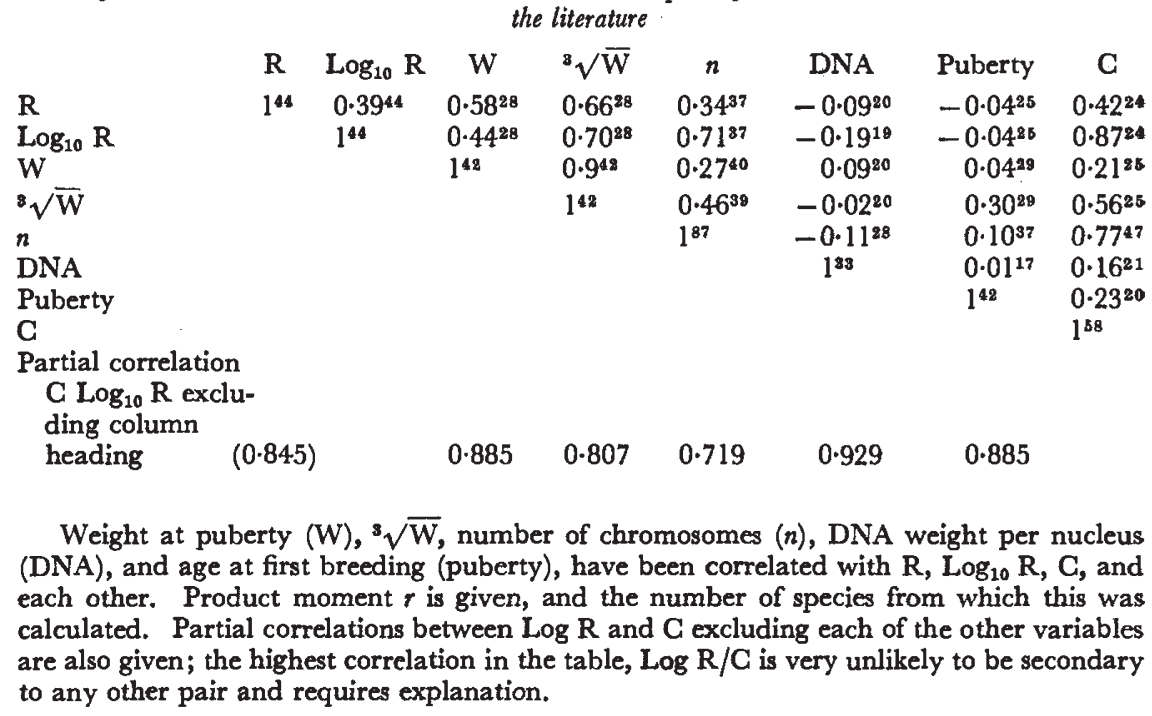

(a) In chiasmate organisms, number of bivalents $(n)$ determines minimum $\mathrm{C}$, and the maximum rarely exceeds $2 \cdot 5 \mathrm{n}$. If chromosome number determines both $\mathbf{R}$ and $\mathbf{C}$ and accounts for the close association, number of chromosomes, $n$, should correlate at least as well with $\mathbf{R}$ or $\mathbf{C}$ as they do with each other. table 1 shows that this is not the case. The finding that C correlates marginally closer with $\log _{10} \mathrm{R}$ than it does with $n$ was a surprise. It emphasises the point of fig. 1 .

(b) It is clear that organisms to the right of fig. 1, with high $\mathbf{R}$ and high $\mathrm{C}$, are larger than those to the left. Larger organisms can presumably afford to produce more sperms, and the clear fitness advantage this gives in multiple mating (or in general polyandrous) patterns of sexual congress might be expected to promote higher sperm numbers.

$\mathrm{R}$ does indeed correlate tolerably well with size, giving $r=0.58$; but this is misleading, because it happens that the weights are in two clusters, a low weight (insects) and a high weight (mammals) group; the points are not normally distributed and the figure is spuriously high.

But $\mathrm{C}$, on the other hand, correlates poorly with weight, giving $r=0.21$. 
So the size of the organism is less closely related to either $\mathbf{R}$ or $\mathbf{C}$ than they are to each other.

The association with size is still suggestive, however. If the path to be travelled by the sperms is a tortuous one in which many losses occur, some linear dimension might be the constraint on sperm number, rather than weight. $\sqrt[3]{\text { weight }}$ was therefore compared with $R$, a simple-minded approximation for duct lengths: $r=0 \cdot 66$, and with $\log _{10} R=0 \cdot 70$. So "path length" may not be without its importance.

These correlations could well be explained, however, by a simpler size constraint; a Drosophila cannot physically produce $3.5 \times 10^{8}$ sperms, which a man does every day. So, some positive correlation between $\mathbf{R}$ and size would be expected; as we have seen, however, there is no close correlation with $\mathrm{C}$, so size cannot be the common determinant.

$(c)$ and $(d)$ So far we have considered associations with $\mathbf{R}$. If $\mathbf{G}$ reflects a copy-choice solution to the problem of mutations accumulated during prepubertal life, then one might expect $\mathrm{G}$ to associate with DNA weight, and possibly with age at first breeding, and perhaps therefore with $R$ via size. Large animals take longer to mature. Table $l$ shows that there is no correlation with either $\mathbf{R}$ or $\mathbf{C}$.

There is another test which can be performed with the same figures. If the high correlation of $\log \mathrm{R}$ and $\mathrm{C}$ arises from their common dependence on a third variable, e.g. chromosome number, their partial correlation, when the third variable is held constant, should be materially lowered. The bottom line of table 1 shows that it is not.

I am left with no direct test of the immediacy of the causative link between $\mathrm{R}$ and $\mathrm{C}$ and can only attempt to disprove the causal theory by examination of its implications and corollaries.

It implies, firstly that about 30 per cent. of chiasmata give unacceptable products, probably because of interpolation/deletion errors. In the Ascomycetes we can observe the products of a single meiosis. Here we find that as a chiasma is progressively more defined by our marker genes, the phenomenon of "gene conversion" becomes more common; in the limiting case, with crossing-over between two contiguous genes, gene conversion occurs in about a third of asci (Whitehouse, 1970). So ascospores show that about a third of chiasmata are not classical recombinations; but, surprisingly in any view, nearly all these meiotic products seem to have unimpaired or repaired function, in contrast to the apparent situation in sperms $(\mathrm{H}$. J. Evans, personal communication, 1968). Perhaps the post-meiotic mitosis makes ascospores unlike gametes because it separates " heterozygous DNA" as Whitehouse suggested. Also evidence from other Ascomycetes, yeasts, does confirm a prediction I made in 1967 that interpolation/deletion errors should occur ("inexact chiasmata ") more in recombinative than in replicative cycles (Magni and Sora, 1969).

What, then, of redundancy in other meiotic products? The theory implies that most ova should prove unacceptable too. The massive degeneration of oocytes in mammals (atresia), has previously been considered a meiotic redundancy (Cohen, 1969); the female Drosophila was seen to fit as well. Unfortunately, although oocyte atresia is known in fishes, echinoderms, and annelids as well as mammals, I have no chiasma data for those females for which I have atresia figures (data in Cohen, 1971). Also eggs have four haploid sets, effectively, which slightly modifies the story because of the 
possibility of "meiotic drive". Egg redundancy figures are shown in fig. 1, however, for comparison with the sperm figures (A, B, C, D).

Pollen grains are an odd case; Prunus and Oenothera both fit (Cohen, 1969), but both are so near to the left of the graph that "redundancy" is here comparable in extent to "accident"; it may be in any case that occurrence of a post-meiotic mitosis (as with ascospores) renders them not comparable with sperms and eggs. (Prunus avium is shown in fig. $1, \mathrm{M}$, but I have no figures for fertile seed production in Oenothera which makes redundancy comparison with other species impossible.)

As well as the above implications, a corollary can be used to test the theory. Faced with the unacceptability of most meiotic products as the price of intra-chromosomal assortment, organisms could either accept the loss of most zygotes or could permit selected gametes only to fertilise. The arithmetic of the theory would lead us to look among prolific marine forms for the first, and to mammals for the second, solution; most organisms would do some of each, but these are testable extremes. I have now located figures for Mytilus (Ahmed and Sparks, 1970) and Crassostrea (Longwell, Stiles and Smith, 1967) which confirm that the number of eggs released is adequate to compensate for the supposed chiasma production error, plus a generous utilisation error as well (fig. $1, \mathrm{X}$ and $\mathrm{Y}$ ). Production error again, then, seems implicated in this "Profligacy of Nature" and is confirmed by the observation that many, if not most, oyster eggs show visible chromosomal aberrance (Longwell and Stiles, 1968).

Experimental work is proceeding with mammals, supported by M.R.C. grant No. G969/14/B, and has already shown good evidence of selection of sperms by female rabbits and mice. That segregation and autonomy of genes of mammalian sperms occurs has been shown at least twice (e.g. Braden and Weiler, 1964; Fellous and Dausset, 1970), so it is reasonable to suppose (contra C. E. Ford, 1972) that some differences in mammalian sperm populations may be referable to their gametic genetic component. It would not be expected, of course, that this selection would eliminate other errors such as translocations, or duplicate or absent chromosomes and the like. It would be a specific filter for a specific production error whose nature and effect we can only hazard guesses about, but whose extent can be inferred from fig. 1 .

I believe that there is now enough evidence for us to consider very seriously the proposal that most sperms are functionless by-products of a necessarily faulty production system, the price paid for the production of sufficient functional gametes. Atretic ova, "gene conversion", apparent profligacy of marine invertebrates, and the complexity of the female mammalian genital tract may all be partial solutions to the problem of defective cross-overs.

\section{REFERENCES}

ADLER, M. T., AND ZOLOTH, s. R. 1970. Copulatory behaviour can inhibit pregnancy in female rats. Science, $168,1480-1482$.

AHMED, M., AND SPARKs, A. K. 1970. Chromosome number, structure and autosomal polymorphism in the marine mussels Mytilus edulis and Mytilus californianus. Biol. Bull., $138,1-13$.

BRADEN, A. W. H., AND WEILER, H. 1964. Transmission ratios at the T-locus in the mouse: inter- and intra-male heterogeneity. Aust. F. Biol. Sci., 17, 921-934.

COHEN, JACK. 1967. Correlation between sperm "redundancy" and chiasma frequency. Nature, 215, 862-863. 
COHEN, JACK. 1969. Why so many sperms? An essay on the arithmetic of reproduction. Sci. Prog., Oxf., 57, 23-41.

COHEN, JACK. 1971. Comparative physiology of gamete populations. Advances in Comp. Physiol. Biochem., 4, 268-380.

DATTA, M. 1970. Re-investigation of meiosis in the male goat, Capra hircus. Linn. Cytologia, $35,344-353$.

eliasson, K., GUstavsson, 1., hULTEN, M., AND LINsTEN, J. 1967. The meiotic chromosomes of the male dog. Hereditas, 58, 135-135.

eVans, H. J. 1968. Personal communication.

Fellous, M., AND DAUsset, J. 1970. Probable haploid expression of HL-A antigens on human spermatozoan. Nature, 225, 191-193.

FORD, C. E. 1972. Gross genome unbalance in mouse spermatozoa: does it influence the capacity to fertilize? In Edinburgh Symposium on the Genetics of the Spermato zoon (ed. R. A. Beatty and Salome Gluecksohn-Waelsch), 359-369. Published by University of Edinburgh.

LONGWEll, A. C., stiles, s. s., AND sMith, D. G. 1967. Chromosome complement of the American oyster Crassostrea virginica as seen in meiotic and cleaving eggs. Can. F. Genet. Cytol., 9, 845-856.

LONGWELL, A. C., AND stiles, s. s. 1968. Fertilisation and Completion of Meiosis in Spawned Eggs of the American oyster (Crassostrea virginica Emelin). Caryologia, 21, 65-73.

MAGNI, G. E., AND SORA, s. 1969. Relationships between recombination and mutation. In Mutation as a Cellular Process (ed. G. E. W. Wolstenholme and M. O'Connor), 186-198. Churchill, London.

OLDFIRLD, G. N., NEWELL, I. M., AND REED, D. K. 1972. Insemination of protogynes of Aculus cornutus from spermatophores and description of the sperm cell. Ann. Ent. Soc. Amer., 65, 1080-1084.

ROBINson, R. 1959. Genetics of the domestic cat. Bibliographica Genetica, 18, 273-355.

WhIrehouse, H. L. K. 1970. The mechanism of genetic recombination. Biol. Rev., 45, 265315.

wILKEs, A. 1965. Sperm transfer and utilization by the arrhenotokous wasp Dahlbominus fuscipennis. (Zett.) (Hymenoptera, Eulophidae). Can. Entomol., 97, 647-657.

\title{
GENETICAL VARIATION FOR ENZYME ACTIVITY IN A POPULATION OF DROSOPHILA MELANOGASTER
}

\section{EXTENT OF THE VARIATION FOR ALCOHOL DEHYDROGENASE ACTIVITY}

\author{
A. J. BIRLEY and B. W. BARNES \\ Deportment of Genetics, University of Birminghom, P.O. Box 363, \\ Birminghom B15 2TT, England
}

Received 25.vii.73

\begin{abstract}
SUMMARY
The variation of alcohol dehydrogenase specific activity in a sample of inbred lines derived from a population of Drosophila melanogaster has been investigated. The results demonstrated the existence of extensive genetical variation for activity which, in part, was not detected electrophoretically. The narrow heritability of individuals in the population was estimated as 20.6 per cent.
\end{abstract}

\section{InTRODUGTION}

THE evidence that has accumulated from the many electrophoretic surveys of proteins leaves no doubt that considerable genetic polymorphism exists within natural populations of many species (Harris, 1966, 1969; Hubby and 